\title{
An Economic Analysis of fog and haze
}

\author{
JING HE \\ North China Electric Power University, No.2, Beinong Road, Zhuxinzhuang, Changping District, Beiji \\ ng 102206, China \\ Email: jij0716@qq.com
}

Keywords : Costs; Benefits; Externalities; Public Goods; Spill

\begin{abstract}
There are various complex reasons for the intensified haze problem in China, but to explore the fundamental economics , I think it is due to that producing and emitting pollution can " generate interest " in current market mechanisms and policy background. Under the drive of interest , environmental pollution intensified. Pollution abatement is one of the provision of public goods, as a result of public goods " totally spillover " feature, market forces alone will certainly not be completed. Expulsion of haze requires the joint action of visible and invisible hands .
\end{abstract}

\section{The 'Generate Interest' Haze}

Discuss haze generation might recall once known as London fog. Britain was the first country in the industrialized world. In the 19th century, as the birthplace of the industrial revolution and the industrial center, London got a rapid development of industry. A lot of fossil fuels, especially coal consumption continues to increase, making the London air pollution intensified, eventually forming the plagued haze, which perplexed the British people nearly a century. The reason of the haze in China are more complicated. Pollution emissions of industries is the number one criminal, besides that, the surge in motor vehicle, coal-based energy consumption structure ,the development of urbanization and the destruction of vegetation are to be reckoned with "accomplices" .All of these have decided the governance of haze to be frustrated and hardly. Look deep into these factors, we will find that they can't escape the invisible hand of the market actually. Under normal circumstances, according to the market mechanism, a commodity only appear on the market at the time of supply and demand exist. But for the haze, we only supply, and there is no demand, it still exists. In my view, it is because that demand generate interest while supply satisfy demand, so that the kind of goods appears in the market. The haze emerges because even if there is no demand, supply it also have economic benefits. Producers benefit from pollution for the low-cost or no cost of emission. Suppose A, B two polluting enterprises, they have the same initial production costs, are all Ci. A business invests in purchasing cleaning equipment, making each product cost increases $\mathrm{Ca}$. B enterprise doesn't make investment and emits pollution directly. The cost of each product in A company is $(\mathrm{Ci}+\mathrm{Ca})$, while $\mathrm{B}$ corporate unit cost $\mathrm{Ci}$. At the same price, the profits of the enterprise $\mathrm{A}$ is a large part of the loss ratio B enterprises. That's how B Company acquire the interest from pollution. Pollution generates economic benefits, which prompts increasing pollution. On the other hand, because there is no demand for pollution, the market can not be pollution self-digest, leading to increasing pollution. 


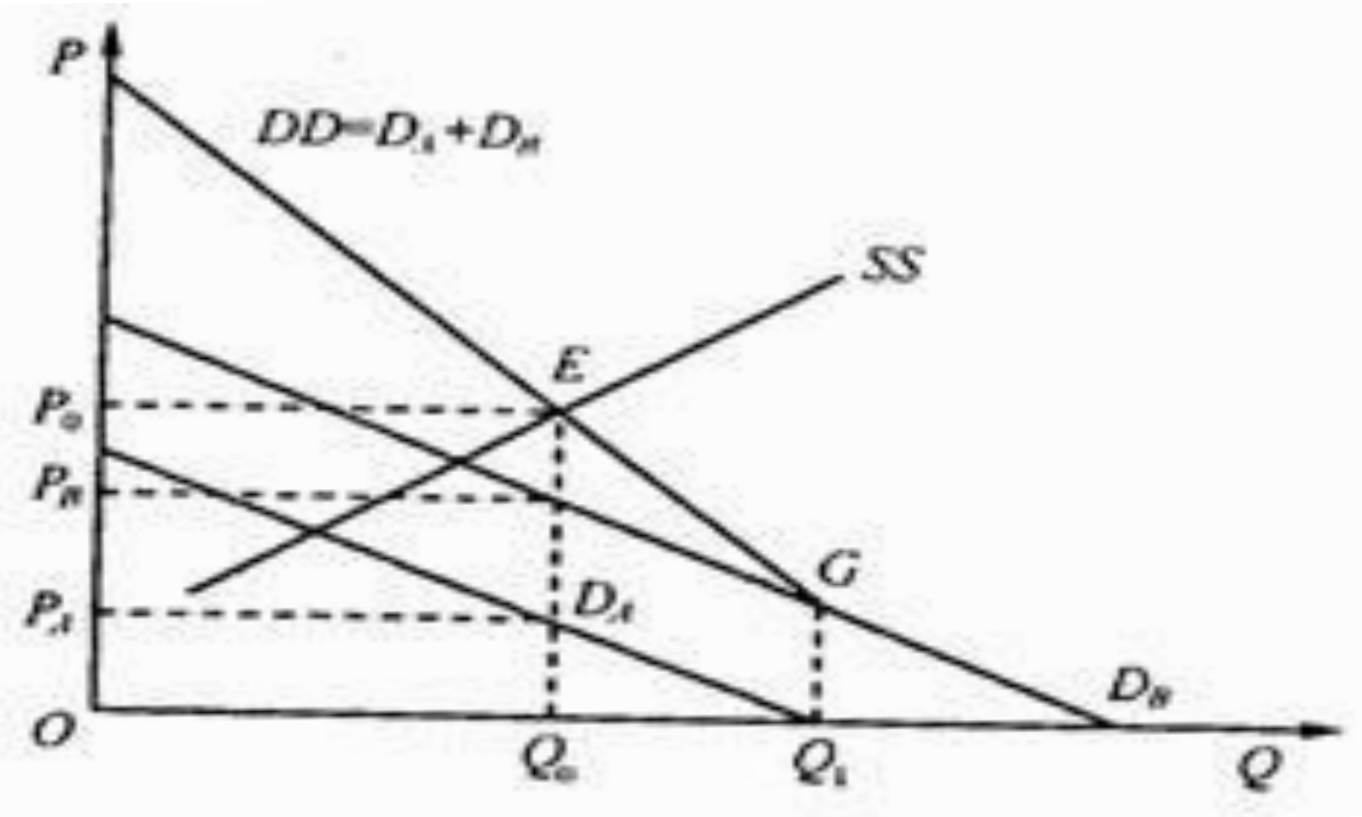

According to the definition of externalities: As long as an economic variable which contains in a economic unity is under the control of other individual, there will be the presence of externalities. When an individual's economic activity subjects to others and cost for it or impose the cost on other entities, negative externalities will come out. Polluting enterprises product in the absence of any environmental protection measures, or the case of punitive measures, assuming a cost of $\mathrm{Cp}$. Pollution emissions from the production leading to environmental damage make a social cost of Cs. Under the drive of benefit maximization, the lucre $\mathrm{Vp}$ is greater than the private cost while less than the social cost, ie $\mathrm{Cp}<\mathrm{Vp}<\mathrm{Cs}$. In this case, although the company won the interest (Vp-Cp), the whole social welfare loss (Cs+ $\mathrm{Cp}-\mathrm{Vp})$.

\section{The Doomed Bumpy Road of Governance}

Once drive out pollution, everyone in the community can enjoy clean air, clean water, beautiful scenery. Anyone who enjoy these beautiful environment will not affect the enjoyment of others, so that pollution governing is non- exclusive and non- competitive. Their interests ( and cost ) spill to a third party. When there is a spillover effect, the demand curve can not contain all the " willingness to pay " and the supply curve can not include the full cost. In this case, the free market price signals would be wrong. Since pollution is almost " entirely spillover ", if it is provided by the market, will result in resources wasting and low efficiency.

There are two solutions. The first one is fully managed by the public sector. Government can form specialized environmental management departments to develop environmental protection laws , enforced by administrative means. on the one hand to manage and penalty pollution from it's headstream, on the other hand to raise funds for special treatment of contaminated areas . But the government providing public goods may leads to low quality and many other issues . Specifically, in the following four aspects : ( a ) lack of competition and inefficient ; (b ) a serious waste , high costs ; (c ) unrealistic, unbalanced development ; (d ) re- form, light results. Second is governing environment by the unite of government and private. Government must take responsibility for the system established. Improving relevant laws and regulations, controlling the sources of pollution , 
collecting special funds. In the meantime, government should supervise private providers' behavior. The private sector use of special funds for environmental management from the government.

In another perspective, pollution regulation is to provide a good environment and good environment is actually a public good. Under the conditions of a purely theoretical analysis, both public goods and private goods can follow Pareto principle to achieve effective supply. Once public goods are provided, each consumer get the same. But the marginal utility of each person is different, that we are willing to pay different prices. In this way, the demand curve of public goods should be obtained by adding each consumer's demand curve vertically. As shown below, assuming line Da and line $\mathrm{Db}$ represent the demand curve for certain public goods of consumer $\mathrm{A}$ and $\mathrm{B}$. The demand curve for the public goods is line $\mathrm{DD}$, that $\mathrm{DD}=\mathrm{Da}+\mathrm{Db}$.

Assuming that the supply curve and the marginal cost of public goods is consistent, then the intersection of demand curve and the supply curve is the equilibrium quantity. Thus it can be seen that the key to effective supply of public goods is that consumers can according to their level of marginal utility derived from the consumption of public goods to express their demands. But in real life, people may hide their preference to avoid paying costs. This requires a rational mechanism to measure consumer preferences accurately.

\section{Summary}

Having known the cause of haze generation, the solution is obvious . That is to increase the cost of pollution emissions, to compress the economic interests of polluting. Then the market will be able to self- regulate, reducing pollution supply. As in 1968, the British government introduced a series bills of air pollution prevention and control, which strictly restrict a variety of emissions, and develop a clear penalties. We can learn from the thought of British haze governance. Consummating the environmental laws and regulations and increasing penalties for environmental violations. In addition to the direct penalties, heavy tax should be imposed on high pollution industry , compressing industry profits, forcing companies to transit to the green direction .

In addition, the low utilization of energy is a major culprit of pollution . Our energy structure is of coal-based. On the one hand, coal energy is high-polluting. On the other hand, it is non-renewable energy sources. At present, China has a very low utilization efficiency of coal. For example, there are less than $30 \%$ energy converted into electricity in coal power generation. Improving energy efficiency, not only can save precious resources, but also an important measure to reduce pollution and protect the environment. However, coal is non-renewable energy source. Government should invest in the development of new energy sources, and promote the development of science and technology. The most important thing is to stand in the level of overall economic development to regulate pollution. Changing energy consumption structure, developing clean energy, and promoting green economy.

Having controlled the source of pollution, there also need a governance on existing environmental. Government should punish the high polluting companies and impose a heavy tax. They can also hire some manage company to decrease pollution, increase green plants and clean environment. Plants can effectively clean the air, stop the sand and clean up the environment. In densely populated London, The per capita green area is as high as 24 square meter. China has a large population. In order to save the land, the city should be rational planned. I think green roofs, green walls and green resident balcony are good ideas. 


\section{References}

[1] Wang Xuguang. Haze governance and economic development from the perspective of economics, [J] (published in late 2013), (8): $24-25$

[2] Jia Kang. Use of fiscal policy and institutional governance haze [J] environmental protection, 2013, (20): $32-34$

[3] Yunying Zhang, Fei Huang, Guofu Wang, Juan Du, Junping Qian. Haze and Urban Planning -after the haze era urban planning thinking and exploration of [J]. tropical geography.2013.19 (21): $41-42$

[4] Fog and haze formation reason, harm and Countermeasures [J] Linfen Meteorological Bureau of Shanxi Pro 041000

[5] Yu Haifeng, Xie Ying: the supply of public services and public sector reform. Financial research, 2008 (10)

[6] Sun Yu: Studies on the operating efficiency of public goods. The Nankai economic studies, 1999 (6)

[7] Lu Hongyou: Theoretical Reflections on the supply efficiency of public goods. The system design of financial research, 2003 (6)

[8] Lei Xiaokang. Analysis of public goods private provision theory [J]. Journal of Xi'an Electronic and Science University (SOCIAL SCIENCE EDITION), 2003,13 (3): 39-43

[9] Li Hongjiang, Pan Hongqing. The theory of public goods providing [J]. Journal of China Coal Economic College, 2000 (10): 61-66

[10] Fan Liming. China public goods market and the voluntary supply analysis [M]. Shanghai people press, 2005 